\title{
Large Deletions in the BRCA1 Gene are not Common in a Set of Familial German Breast Cancer Patients
}

M. Maringa, S. Uhlhaas, E. Kreyer,

W. Friedl, P. Propping and R.K. Schmutzler

Institute of Human Genetics and Department of Gynecology, University of Bonn, Germany

Haplotype analyses showed that about $90 \%$ of hereditary breast cancer cases are caused by mutations in the genes BRCA1 and BRCA2. However, the mutation rate in these two genes was not as high as expected. In about $10 \%$ of the Dutch breast cancer families large deletions of whole exons (exon 13 and 22) of the BRCA1 gene have been described. These deletions are not detectable with the common approaches such as SSCP, PTT and direct sequencing (PetrijBosch et al., Nature Genetics 1997). We examined 40 patients suspected for hereditary BRCA1 deletions.
Genomic DNA was isolated from fresh blood samples. Deletions in exons 13 or 22 were examined by amplification of these exons; the PCR-products were separated on agarose gels. Southern analyses (DNA digestion with BgIII or Hind III and hybridisation with probe p11 and probe p14-24) were performed.

We did not find any large deletion in our 40 German breast cancer families with the PCRbased method. Southern analysis showed an additional band in one family. Further examinations including cDNA analysis have to be performed in order to find out whether this aberrant band results from a single base exchange in the restriction site, or from a large deletion.

\section{Acknowledgment}

This study is supported by the Deutsche Krebshilfe. 


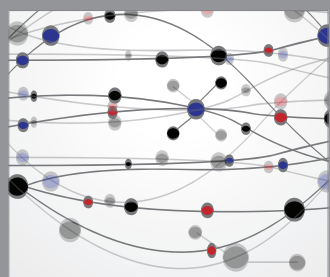

The Scientific World Journal
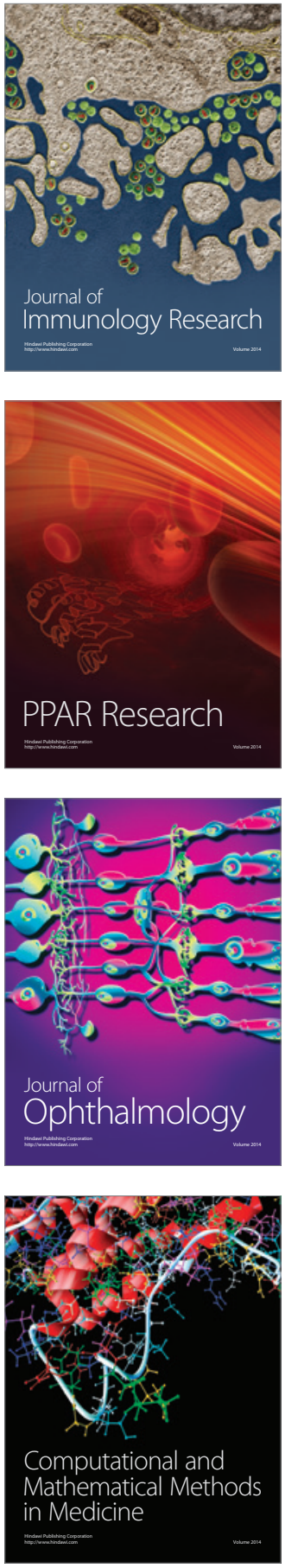

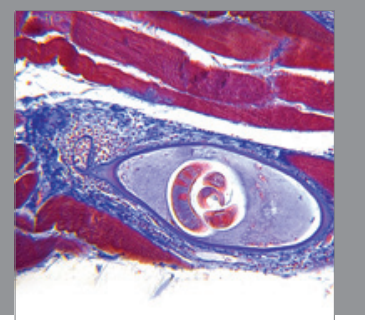

Gastroenterology

Research and Practice
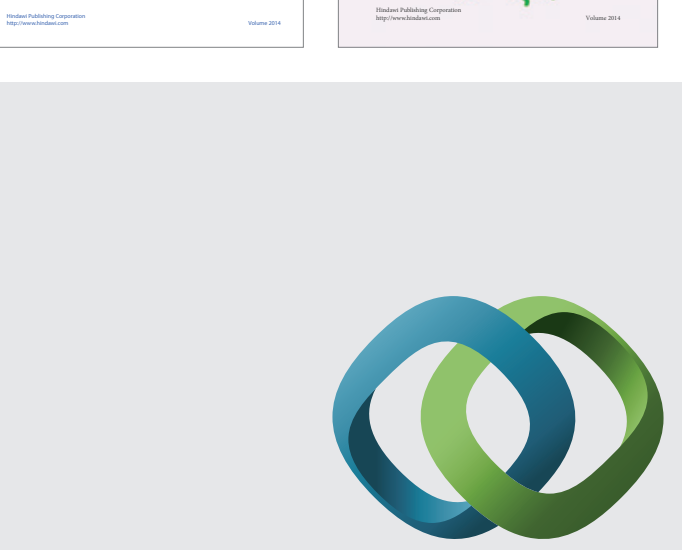

\section{Hindawi}

Submit your manuscripts at

http://www.hindawi.com
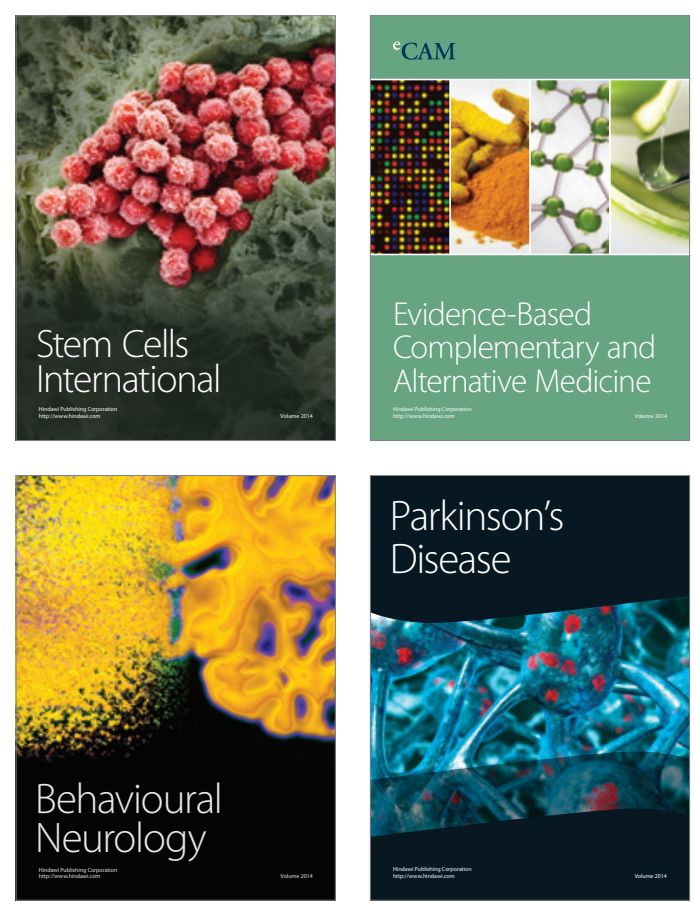

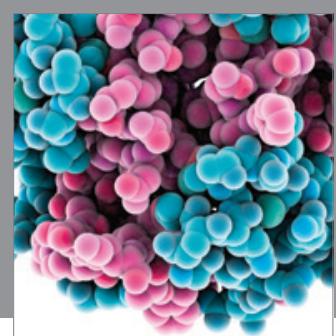

Journal of
Diabetes Research

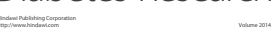

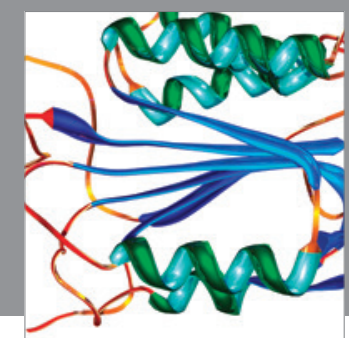

Disease Markers
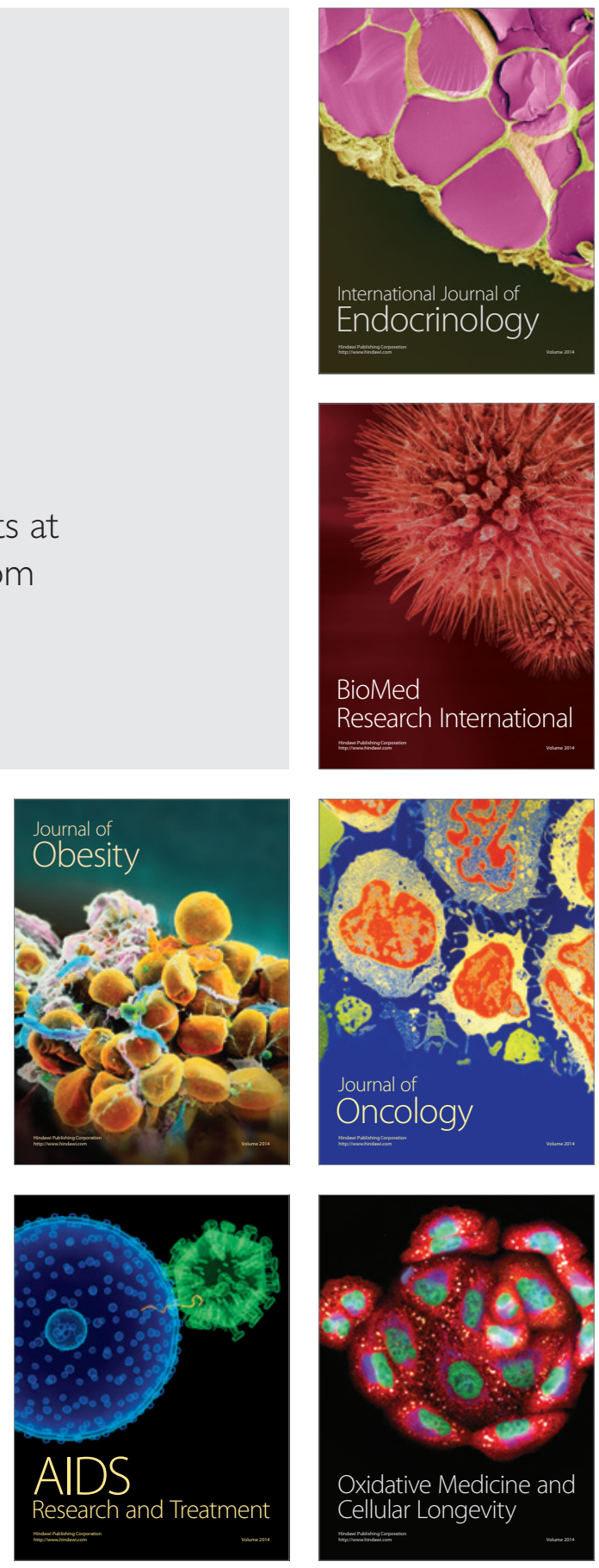